\title{
SOME FINANCIAL AND ECONOMIC PROBLEMS IN RAILROAD RECAPITALIZATIONS
}

\author{
JOSEPH R. WARNER*
}

The American railroad capital structure is being remodeled to such an extent by the reorganizations now under way that the greatest care and discernment should be exercised as to possible consequences to the industry as a whole. It is erroneous to assume that the problem concerns the bankrupt lines only; even though these represent approximately $30 \%$ of the mileage owned and (based on 1936 results) between a fifth and a quarter of the gross revenues. The potential consequences of policies adopted ramify to the presently solvent lines in a degree which it would appear is inadequately recognized.

The diversity of character between the individual situations, in part inherent and in part the consequence of a variety of factors, makes it impracticable to formulate hard and fast rules of capitalization which would operate effectively and equitably. Fortunately, the difficulties of legislating along this line seem better appreciated and legislation heretofore proposed now appears in abeyance. The purpose of this discussion, therefore, is not a futile attempt to prescribe rigid rules for the formulation of capital structures, but to point out some of the larger aspects of the problem which seem to merit especial attention lest, by oversight, irreparable damage be done to both the industry and the holders of its securities. Space limitations have confined this article to a discussion of the more outstanding features only.

\section{Total Capirarization and Boox Valure}

Obviously, the over-all capitalization must reflect the corporate picture. But, in doing this, sight should not be lost of the fact that the railroad industry is a stringently regulated public service enterprise. As such it partakes of characteristics which need to be kept in mind both in the public interest and in that of the industry itself.

The Interstate Commerce Commission's approach to the problem is that of determining upon a capitalization figure which it deems appropriate in the light of

- Maintains organization in Newark, N. J., for analysis of railroad operating results and financial problems, especially those pertaining to reorganization; acts in advisory capacity to protective committees, institutions and railroads. Author of various articles and addresses on railroad subjects including: Reorganization of the Rail Capital Structure (address, 1933 Convention, Associated Traffic Clubs of America); The Mechanics and Prospective Benefits of Railroed Reorganization (address, 1940 Convention, same as. sociation); Some Aspects of Present Trends in Railroad Reorganization Practice and Policy (Dec. I939) 20 Savincs Banx J. No. 10, p. 7. 
the record. Beyond directing that the value of any property used in railroad operation shall be determined on a basis which will give due consideration to earning powrr, past, present and prospective, and all other relevant facts with only such effect given to reproduction and original costs and investment therein as may be required under the law of the land, Section 77 is wisely silent on the subject of an appropriate capitalization. This must, under prevailing economic conditions, remain a matter of collective judgment, tempered by adequate recognition of the limitations of the human mind when attempting to forecast the future.

There is, however, a feature collateral to this subject which it may here be appropriate to discuss. This is the cost at which the property taken over by the new company should be set up on its books. In the railroad construction days of the last century, book values were largely a derivative of capitalization. In other words, the latter rather than the former was the starting point and not infrequently the capitalization was a matter of choice or expediency. 1

If we were now to follow the practice of the early construction days, the cost of road and equipment would likely be set up on the books of the reorganized company to balance with the capitalization approved by the Commission after due recognition of other assets, liabilities and reserves. But that this would be wise or equitable seems very doubtful, even though the accounting would conform to the theory of cost to the new owner. Original cost of railroad property to the industry itself would seem more important than the somewhat fortuitous subsequent cost of segments thereof to individual corporations.

Conservatism may possibly require that, in fixing upon the total capitalization issuable in reorganization, realism be the watchword. The directions as to determination of value cited from Section 77 point this way. But because recapitalization may in some instances have to cut deeper than original cost, it would not seem to follow that the Commission's best guess as to what under present disturbed conditions might appear to constitute the most appropriate capitalization, should necessarily control the amount set up on the books of the new company as the cost of the property. Nothing is gained by adjusting the book value of the property to reflect approximately $\$ 100$, or any other particular figure, per share of new common stock.

It would seem that the cost of the property as set up on the books ought to be tied to something more fundamental and definite than mere human opinion at a particular time as to what may appear an appropriate capitalization. for a particular corporate parcel of a publicly regulated enterprise. Railroad reorganizations take place in depressions, not in eras of prosperity. Consequently, the amount of cap-

\footnotetext{
2 This approach left the door open to inflation of book values. Subsequent reorganizations, however, and plowing back by stronger roads of earnings which might have been distributed as dividends, brought the net capitalization of the industry as a whole to an amount far below the Commission's computation of original cost. Even if we deduct from the latter the Commission's estimates of accrued depreciation, the balance still exceeds the net outstanding capitalization of the carriers. Likewise, the reproduction cost of the properties less depreciation, as computed by the Bureau of Valuation in Ex Parte 123, very substantially exceeds the net outstanding capitalization.
} 
italization approved may vary widely, dependent upon the mood of the moment as to the outlook for the future.

Broad public policy may require that the cost of property devoted to public service should not be overstated. The present regulatory concept in the electric light and power industry is toward conforming the accounting records of investment to original cost at the time of dedication to public use with, of course, due recognition to additions, betterments and retirements. Conversely, the original cost of property now devoted to transportation and taken over by a reorganized railroad company, would seem to be the minimum at which it should be set up on the books irrespective of what lesser amount of capitalization the regulatory Commission may approve under the stress of present economic conditions and outlook. Not only do retirements versus replacements and additions and betterments make the property investment account trend in the direction of original cost of the property currently in use, but this cost, as constructed by the Bureau of Valuation, is a matter of record rather than estimate for more than $70 \%$ of today's property. This original cost so set up on the books should, of course, be offset on the liability side by the depreciation reserves required under the Commission's accounting regulations. ${ }^{2}$

It would seem somewhat at variance with American concepts for the same regulatory commission that fixes rates to determine corporate capitalization largely on the basis of the resulting earnings and then to make the property investment record conform, after according due recognition to other assets and liabilities, to such a mere judgment figure. The fact that the integrity and sincerity of purpose of the membership of the present Commission is beyond question does not warrant what in principle would tend to verge upon a vicious circle.

It is undoubtedly true that some part of the present railroad plant of the country has become obsolete. Conceding that a considerable part of the thin traffic and interlacing branch lines of the numerous individual companies must ultimately be scrapped, the two, investment record and physical property, should go hand in hand. If, as and when the Commission is willing to face facts and permit large scale abandonments, then the property account must be reduced. But, until the Commission does this, the arbitrary scaling of the investment account below original cost without a corresponding elimination of the superfluous property thereby represented, is not only unfair to the industry and its security holders, but misleading to the public. So long as the latter, through regulatory commissions, requires the maintenance and operation of this mileage, the owners of the enterprise would appear entitled to have it recorded on the books at no less than the fair original cost of the property currently dedicated to public use. This would avoid among other evils, the danger of an exaggerated statement of earning power on the investment.

The excess, if any, of original cost over the capitalization approved by the Commission should be set up (after due allowance for other asset and liability items includ-

\footnotetext{
${ }^{2}$ Actual confusion has been injected into some of the present reorganizations by the past practice of stating equipment book values after reorganization at net (depreciated) figures instead of on the basis of cost with the offsetting acerual of depreciation on the liability side of the balance shect.
} 
ing reserves) on the liability side of the balance sheet as a reorganization adjustment account ${ }^{3}$ purporting to reflect the excess by which assets exceed liabilities, reserves and capital. If and when prospective abandonments take place, these might well be charged, in whole or in part, to this account (in so far as it suffices) against the elimination of such property from the investment account. Ultimately the Commission may approve provision of a reserve (chargeable against earnings) for retirements and other obsolescence in lieu of the present so-called capital funds.*

There is, however, a much more vital reason for such a reorganization adjustment account reflecting the excess of the property investment at original cost plus other assets over the sum of the approved capitalization, reserves and other liability items. Abandonments presumably cannot be made without a write-off on account of the property retired. If there is no adjustment account such as here discussed, to what would the write-off from the property account reflecting abandonments be charged? These reorganized companies cannot by the very nature of things accumulate any substantial profit and loss account for a considerable period of time. If in the interim, a company which would like to effect substantial abandonments of superfluous and unprofitable mileage is faced with the problem of thereby incurring a deficit in its balance sheet, is this not in itself likely to be a deterrent, if not a possibly controlling factor, against the abandonments? Over the last decade we have experienced many deferred retirements of obsolete equipment because the current income accounts could not stand the write-off reflecting an inadequate reserve. 5 The situation here would be much worse because there would be no profit and loss account against which abandonments of property ${ }^{6}$ could be charged. Prudence and provision for the future, therefore, would seem to require an account to which such abandonments might be charged lest the very lack of such an account would in itself constitute a managerial barrier to the abandonments. It would, therefore, be most unfortunate if, in an effort to have the property investment account reflect the approved capitalization (with, of course, due recognition to other assets, liabilities and reserves), the Commission were to ignore original cost of the property taken over as the minimum at which it should be set up on the balance sheet.

At best the capitalization approved by the Cammission will labor under the burden of human fallibility and must inevitably reflect in some degree the state of opinion under present world chaotic conditions. If in the future it develops that the

\footnotetext{
- The Commission has made provision for such an account in its standard balance sheet, but there seems to be a tendency to look upon the question of the basis upon which the investment account should be established as largely a matter of accounting detail rather than as fundamental policy.

- These so-called capital or A\&B funds, which are 2 vital part of present-day plans, were discussed at length, together with sinking funds and other features, in an article by the writer in Railroad Reorganization Practice and Policy (1939) 20 Savings Banx J. No. 10, p. 7.

- To meet this situation the Commission in 2 number of specific instances approved a direct charge to profit and loss of the write-off reflecting this inadequacy.

- The discussion here pertains to the abandonment of mileage and property and not to the retirement of equipment. Under the present accounting practice the total write-off of equipment retirements would be charged to equipment depreciation reserves even though the amount of the write-off might exceed that portion of the accumulated reserve which, upon analysis, would be applicable to the units retired.
} 
Commission erred in undervaluing the appropriate amount of capitalization, the true picture will not have been lost in obscurity. And the attainment of a reasonable rate of earnings on the actual investment would not be misconstrued as an extravagant return by reason of an understated property investment. Uniformity in recording book values would permit true appraisal of the situation at any time.

\section{Fixed Charges and Earning Power}

When we turn to the subject of fixed charges and consider these realistically, it would seem that the whole enterprise and commitments in connection therewith, rather than only the property corporately owned, enters the picture. It is clear that fixed charges including rentals cannot be too high in relation to earning power, but neither should they be too low because securities carrying a return which is not fixed require a higher coupon rate. The determination must be based on collective judgment. But this in turn should be founded on an adequate comprehension of the earnings picture. Earning power must obviously be the determining factor in the approval of an appropriate maximum amount of fixed charges. It behooves us, therefore, to examine into this matter of earning power as it may really exist rather than accept at face value whatever may be the reported earnings under some prescribed form of accounting. The objective sought is, of course, future earning power. The difficulties involved in adequately gauging this are innumerable. But the least we can do is to clearly understand and correctly visualize past and present earning power as these may bear upon the future, envisaging in the process the scope of the operations as such, including property utilized though not owned, without rigid adherence to what is comprised within the corporate ownership. Resort to this approach leads to a consideration of the problems discussed under the succeeding subheadings.

\section{The Effect of Variable Maintenance}

First among the distinctions between earning power and reported earnings is the effect of variable maintenance. The important part which maintenance plays in shaping net can most readily be sensed from the statement that over the last seventeen years, 1923 to I939, inclusive, maintenance expenditures of Class I roads averaged double the amount carried down to net. In the eight-year period r923-r930 the ratio was 1.89 for all Clàss I roads, 2.29 for seven important lines now in bankruptcy, and r.85 for the remaining Class I roads. When we come down to the last six years, however, we find that the ratio of maintenance expenditures to net on the bankrupt lines averaged six to one whereas that of the other Class I roads averaged only two to one. Other evidence confirms the relatively high maintenance on most of the bankrupt lines as compared to normal requirements at prevailing levels of traffic.

It is not here intended to imply that there is any necessary or normal relationship between maintenance and net, or that, if the particular roads now in bankruptcy were out of the courts, the relationship between their maintenance expenditures and 
net should reflect no greater proportionate change from the predepression period than that which has occurred in the instance of the remaining roads. There are other factors which enter into the equation. Among these are taxes, operating rentals and relative changes in rate levels. It may, however, be said that, if the maintenance expenditures of these bankrupt roads in relation to gross revenues had been stepped up proportionately no more than those of the other Class I roads, the ratio of maintenance to net would probably be in the neighborhood of three to one. From whatever angle the problem may be approached, it is apparent that the net of the bankrupt lines, by reason of the pyramidal effect thereon of relatively heavy maintenance expenditures, is supersensitive to, and will sharply reflect, any appreciable change in maintenance policy. The important point here is not whether the maintenance expenditures of the bankruptcy period may have been required by previous neglect. The heart of the problem is whether the amount of maintenance charged to operating expenses in the period for which the net is accepted as more or less indicative of prospective minimum earnings, was in excess of the normal current requirements under the volume of traffic and conditions then existing. If it was, the earning power of the property under the conditions then prevailing was understated by the excess of the expenditure over normal current maintenance requirements.

A subdivision of this subject of maintenance which in itself has a bearing on reported results is that of depreciation. Under current railroad accounting practice, depreciation is prorated over the estimated service life of equipment. While some part of this depreciation reflects the time element, a substantial part obviously reflects usage with its resultant wear and tear. But no consideration is given to the proportion of the latter involved in apportioning the depreciation requirement to the individual yearly income accounts. The result is that in years of high activity, usage and earnings, the depreciation absorbed in operating expenses is probably less than a fair pro rata of the prospective useful life consumed in that period. On the other hand, when traffic volume, usage and net are low, the expense account has to absorb the same amount of depreciation as in a peak year. Consequently, the factor of equipment depreciation tends to bear heavily upon the reported net of poor years just as it tends to weigh lightly upon the operating costs of good years.

\section{The Character of Joint Facility Rentals}

Another distinction between the earnings as reported under prescribed accounting and a more fundamental picture may be found in the somewhat anomalous treatment the accounting accords joint facility rentals versus those for leased roads. The fault, if such it may be, inheres in Section 77 itself which, following the long established accounting procedure, specifies that fixed charges include besides interest on funded and unfunded debt and amortization of discount, "rent for leased roads," thus by direct implication excluding joint facility rentals from the category of fixed charges. It may, therefore, be pertinent to note just what are the distinctions and similarities between joint facility rentals and rentals for leased roads.

${ }^{\top}{ }^{377}(b)(4)$. 
If $\operatorname{Road} A$ leases $\operatorname{Road} B$, the rental therefor is treated as a fixed charge. If, however, Road $B$ reserves the right to operate over the scgment of its property used by $\operatorname{Road} A$, with the rental payable by $\operatorname{Road} A$ based on proportionate usage, this rental (joint facility) is not treated as a fixed charge but as an operating cost in determining net railway operating income. ${ }^{8}$ The ostensible distinction between these and the dissimilar treatment accorded them in the accounting statement, are presumably predicated upon the premise that Road $A$ rental varies in proportion to relative usage. The significant fact is that although actual usage may vary widely, relative usage usually does not. Barring some fundamental change in the relative position of Roads . $A$ and $B$, the usage by both roads of the joint segment tends to move more or less in unison. Consequently, the rental, although theoretically variable, is in reality largely a fixed requirement and to that extent not entirely dissimilar ${ }^{9}$ to the rent paid for lease of road which is treated as a fixed charge and not recognized in the determination of net railway operating income. The soundness or unsoundness of this differentiation in accounting treatment, dependent as it is on whether the use of a particular facility is exclusive or joint, is outside the purview of this discussion. We are here concerned with a proper recognition in reorganization of the fundamental situation as we find it rather than in a discussion of what might or might not be a more appropriate and consistent handling of the accounting record.

The relatively fixed character of joint facility rentals irrespective of volume ${ }^{10}$ tends to make the residual net earnings of a road with heavy joint facility rentals highly volatile in character. It is a simple story of the deduction of a relatively fixed requirement from a variable. And when the earnings of the roads in general are depressed for a protracted period of time, the earnings, or more specifically the net railway operating income, of roads bearing the burden of heavy joint facility rentals, are especially depressed.

The danger lies in assuming that the extremely poor depression period net results of a road having high joint facility rentals is symptomatic of disproportionately low traffic volume, adverse operating conditions or inherent deficiencies. In reality a large part of the problem in such instances is due to the absorption of joint facility rentals in the determination of net, whereas if these rentals were for the exclusive rather than joint use of property, they would not be deducted in the determination of net but in-

\footnotetext{
- For the benefit of those not familiar with railroad accounting terms, it may be said that net railway operating income is the net remaining after deducting all operating expenses including maintenance and depreciation, exes, hire of equipment, and so-called joint facility rentals, of which joint terminals aecount for a substantial proportion. If a railroad owns its own terminal properties, the interest on the bonded portion of the cost thereof is not recognized in the computation of net but is included in fixed charges 25 is any other interest. But if the terminal is jointly used by two or more roads on a user basis, the rental (joint facility) is deducted in the determination of net.

- There is, however, this distinction. Taxes paid on leased railroad properties are charged directly to the tax account whereas tax payments in connection with joint facilities are included in the rental. Consequently, before joint facility rentals can be treated as the substantial equivalent of fixed rentals, adjustment needs to be made for the tax factor.

${ }^{20}$ Change in volume here pertains to that reflecting the business level generally rather than to that reflecting some change peculiar to one road alone. The latter would, of course, tend to change the pro portionate amount of joint facility rentals paid another line or terminal company.
} 
cluded with fixed charges. ${ }^{11}$ And conversely, just as the present accounting practice with respect to joint facility rentals tends to present the earning power in a period of depression in an adverse light, the net railway operating income of a road with such rentals is likely to respond much more strikingly to an improvement in business than that of a road whose payments for the use of property of others falls within the category of fixed charges. Heed, therefore, should be given to the items which go into the determination of net in a particular case and the latter should not be accepted literally as all-conclusive and comparable between roads.

\section{The Character of Equipment Rentals}

What is said here respecting joint facility rentals might be said in substantial degree with respect to that portion of equipment rentals which purports to represent capital service as distinct from that portion which purports to represent reimbursement to the owner of the equipment for maintenance and depreciation and taxes. However, this much can be said in favor of the present method of deducting equipment rentals in determining the available net. A substantial part of these rentals, viz., the maintenance and depreciation portion, is in fact an operating expense even though the capital service portion is not. Also, these rentals should reflect varying volume of traffic in greater degree than the joint facility rentals. If the traffic carried in refrigerator and tank cars does not move, the railroad has no rental payment to make thereon. The reason that hire of equipment rental does not follow the trend of traffic volume more closely is largely attributable to the following fact. A road originating much traffic and with an adequate complement of cars to handle such traffic, may find a lack of demand and a consequent loss of per diem credits in a period of low business. When business expands and these cars are more fully utilized in shipments off line, they produce credits which tend to offset an expansion in private mileage rentals and thus hold down or even decrease the net equipment debit at the very time when an expanding traffic would lead one to expect an increase in the net debit.

\section{Income Bonds Versus Preferred Stock}

While failure to accord adequate recognition to the factors discussed above would bear initially on the amount of fixed interest bonds the Commission may be willing to approve, it also bears on the amount of contingent interest bonds which it may deem appropriate. Fortunately, the former prejudice against these has largely disappeared. The chief problem now seems to lie in determining their appropriate amount in each particular case and the specifications as to the terms of the interest payments thereon.

\footnotetext{
12 To the extent that joint facility rentals after the elimination of the tax factor therein, are for practical purposes more in the nature of a fixed charge than operating cost, their inclusion in the earnings computation rather than in the fixed charges tends to some inconsistencies as respects coverage factor between roads with heavy joint facility rentals and those which are free of this burden. This, however, is 2 less important factor than the phase outlined above.
} 
Among the legitimate reasons for this type of security is the fact that these bonds are issued against securities which were bought by the original investors as bonds and not as stock. Fairness and equity demands that the position of present investors be disturbed no more than the minimum necessary to effect a sound reorganization in the public interest. To substitute stock for bonds where a contingent interest obligation would be justifiable seems to constitute an unwarranted and needless violence to the rights of a creditor. Public interest may well involve the substitution of contingent for fixed interest, but relegation of a creditor to the level of a mere partner should be limited to the extent absolutcly necessary.

Among other valid reasons for retaining the obligation character of a bond, even though interest thereon is reduced to a contingent status, is the tax saving as against the substitution of stock. To substitute $5 \%$ preferred stock for $4 \frac{1}{2} \%$ income bonds (the prevailing rates adopted in the Commission's plans) where the latter may not be inappropriate, increases the combined income tax and capital service burden upon the corporation almost $40 \%$ as compared to the requirement on income bonds.

Admitting that a deliberate effort by a corporation to substitute bonds for stock now outstanding in order to avoid taxes may be subject to criticism, this is not involved in the slightest degree in the present reorganizations. The obligations for which income bonds are proposed to be issued in whole or in part, were validly issued as bonds and in substantial part under I. C. C. approval. To transform them into stock in order to subject to income taxation the earnings applicable to interest, would be ironical indeed in a proceeding ostensibly designed, among other things, to strengthen the financial position of the industry.

An optional right to the holders of income bonds to convert into common stock is a very different thing from an undue substitution of preferred stock for income bonds in the first instance. The conversion right, when it operates, not only concedes to individual investors their preference but builds up the equity of the common and its prospective value as a financing medium. In contrast, the enforced substitution of preferred stock for income bonds beyond the amount reasonably necessary, diminishes the potentialities of the common by sharply increasing the servicing and tax requirements ahead of it. The differential of almost $40 \%$ previously cited will increase as tax rates progress upward.

Probably the clinching argument in favor of the issuance of income bonds rather than preferred stock to such extent as may not be unreasonable, is found in the fact that the saving between the two, if applied to a live sinking fund on the bonds, would retire the entire issue in less than thirty years. This computation is based on an assumed retirement at par whereas a large proportion of such bonds, especially where the issue is relatively substantial in amount, could undoubtedly be acquired much below par and complete retirement thereby accelerated.

A legitimate limitation upon the issuance of income bonds rather than preferred stock would seem the avoidance of such amount of bonds as might bulge out beyond the point of reasonableness and, to that extent, tend to create an unbalanced struc. 
ture. But this last statement should not be misconstrued as implying that the fixed interest bonds, contingent interest bonds, preferred and common stocks, should all bear some fairly standardized and circumscribed relationship to each other. The comparative earning power of different properties and their stability or instability (when examined factually rather than superficially on the basis of pro forma results) make clear that rational capital structures have to be cut to the individual characteristics of each property and not to some preconceived standard pattern merely because the latter may look more symmetrical on paper.

The present-day reorganization trend avoids some of the major objections in the past to income bonds. In earlier years these frequently contained no protective provisions with respect to accumulation of unpaid interest. Then the pendulum swung the other way and some awkward situations were set up with interest rigidly cumulative. The present trend strives toward the happy medium of limiting the accumulations to a specific amount, thereby affording reasonable protection against undue diversion of earnings while at the same time avoiding accumulations beyond prospective ability to liquidate.

\section{Preferred Versus Common or Capital Stock}

Unless it is desired that there be more than one series or strata of income bonds, we have left for discussion the categories of seniority, if any, into which the capital stock of the company should be classified. Should this capital, which represents partnership equity, be split into various classes of seniority, each with clearly prescribed preferences and limitations, or would it be better to issue it all as simple capital stock?

The necessity of giving due recognition to existing seniority of claims of the old creditors falling heir to the stock of the reorganized company is frequently such that the qualitative differences cannot readily be adjusted quantitatively. The question, thereiore, of the appropriateness of issuing some of the capital stock in the form of one or more preferred issues of specified seniority rights would seem controlled by expediency. This may be unfortunate, but investors have some rights and these should not be subjected to any greater relative disturbance than necessary. The same is, of course, also true with respect to actual disturbance. The latter, however, seems to be one of the first requisites of a reorganization.

But the mere fact that expediency and the realities of a particular situation may necessitate splitting the new stock into two or more categories of seniority does not preclude frankly looking the situation in the face. To do so should be a material aid in avoiding this subclassification of stock beyond the point necessary to meet individual requirements with respect to the relative seniority position of those claims allotted stock in reorganization.

Railroad preferred stock has always been more or less a hybrid security. The title "preferred" has naturally appealed to some investors, many of whom have no doubt failed to sense the real place such stock occupies in a complicated financial structure 
embracing all kinds of senior obligations as well as those like rentals which are not disclosed in the balance sheet. Industrial preferreds are usually in a quite different class, frequently constituting a first claim on both assets and earnings. But if there is any disagreement as to the hybrid character of railroad preferred stock in the past, there would not seem much warrant for contending otherwise as respects the prospective future. If non-cumulative, every year that goes by without receipt of dividends is apt to leave the preferred issue but little better off than at the beginning of the period. And the so-called capital or $A \& B$ funds ${ }^{12}$ tend to contribute to this condition. On the other hand, the cumulative feature, even when unlimited, has not added much to the market value of the preferred stocks of companies which have been unable to establish a consistent dividend record, even though such accumulations have pretty effectively shoved the common further off into thin air. And the preference as to assets in vogue for the last couple of decades and being incorporated in present plans (many of the old railroad preferreds were preferred as to dividends only) likewise seems to have added but little to the market recognition of the senior issue although it has further diminished whatever otherwise apparent value might attach to the common.

In short, it is not entirely clear that, as an abstract proposition, there is any appreciable advantage gained by a railroad company in splitting its capital stock into two or three varieties, one superior to another. On the contrary, it would appear to be at least an open question whether something is not lost. Common stock which may occasionally pay a dividend and at least on the record appears to earn something, might conceivably be utilizable for some tinancing in a prosperous era. No par common or capital stock is, or at least should be, available for sale at any reasonable figure meeting with I. C. C. approval, irrespective of what may be the book value of the previously outstanding shares. Certainly it cannot be so availed of if subordinate to a substantial amount of preferred stock when the latter has a sketchy dividend record. But neither should it be assumed that the preferred in itself would constitute an acceptable financing medium. To be so available, it would have to be salable at a market value not too far out of line with its preferences as to assets and dividends.

To provide that the preferred may participate with the common and especially in all earnings in excess of a low rate of dividend on the common, would seem about the best way of voiding whatever chance there might be of the common ever serving as a financing medium short of the millenium. At the same time this participation right would seem to add but little to the prospective usability of the preferred issue for financing purposes. A conversion right appears sounder and more logical. It offers the preferred shareholder the desired protection against inflation (in so far as the railroads might derive any benefit therefrom) while at the same time it builds up, if and when exercised, the equity for the common by decreasing the amount of senior stock. Convertibility aims in the direction of a single broad class of capital stock even though the exigencies of particular situations do not permit this initially.

\footnotetext{
II See note \&s swpra.
} 
Accordingly, in the light of the uncertain quality of preferred stock and its doubtfu! advisability, except as necessities of a particular reorganization require subdivision of the new capital, it is apparent that there must be severe limitations on the extent to which such stocks can be made cumulative. On the other hand, if entirely non-cumulative, all earnings otherwise applicable to dividends might be diverted to additions and betterments with the common a potential beneficiary of the diversion at the expense of the preferred. The present tendency therefore is to provide limited accumulations dependent upon earnings which seems about as far as it is possible to go, notwithstanding that a modest variation in managerial maintenance policy may readily constitute the difference between a substantial rate or no earnings at all applicable to the preferred.

\section{Conclusion}

From what has been said ${ }^{18}$ it must be apparent that any effort to judge the soundness of a proposed capital structure either before or after the fact, on the basis of the ratio borne by each class of security to the aggregate capitalization, is not only futile but illogical. To cite but one illustration: joint facility and fixed rentals, for instance, reflecting property used but not owned, do not enter into the total capitalization or the property investment account. And yet these are vital considerations in the determination or limitation of fixed charges. Different factors enter into the question of over-all capitalization versus the subdivisions thereof. Earning power, although of primary importance from practically all angles, must be gauged broadly in the light of all the relevant circumstances and not solely on the basis of whatever happen to be the reported results of an arbitrarily chosen period.

Moreover, when considering future earnings, adequate recognition should be given to the fact that the railroad industry may not unreasonably be assumed to be in a transition stage at the present time. If and when we get out of the depression, traffic and earnings should improve. If, however, the railroads should not share adequately in the recovery, this would then be an established fact and not a matter of opinion. Under such circumstances the roads would have to adjust themselves to the changed conditions. Further strenuous efforts would have to be made to reduce expenses by eliminating duplicated or other services not economically justified.

\footnotetext{
12 There are other features which also require the most careful attention in the development of a plan. Among these are sinking funds, emergency financing provisions and the possible desirability of a reserve chargeable to operating expenses in lieu of the so-called capital or A\&B funds. Space limitations proclude their discussion here. See note 4, supra.
} 